\title{
Adoption of Exercise and Readiness to Change Differ Between Whites and African-Americans with Hypertension: A Report from The Ohio State University Primary Care Practice-Based Research Network (OSU-PCPBRN)
}

\author{
Randy Wexler, MD, MPH, David Feldman, MD, PhD, Douglas Larson, BS, \\ Loraine T. Sinnott, PhD, Lisa A.Jones, PhD, and Jared Miner, BS
}

Background: Hypertension is a major cause of morbidity and mortality in the United States and disproportionately affects African-Americans. A cornerstone to treatment is nonpharmacologic lifestyle modifications. Despite such recommendations, many patients fail to exercise.

Methods: An anonymous survey $(n=285)$ of hypertensive patients cared for at 2 offices within the Ohio State University Primary Care Practice-Based Research Network. Survey questions included demographics, recommendations for diet, and exercise lifestyle modification for reducing blood pressure. Questions were phrased as multiple choice or based on Prochaska and DiClemente's readiness to change model.

Results: Of the 244 respondents, $57 \%$ were women and $43 \%$ were African-American. The income of African-Americans was significantly lower than that of whites. Exercise and increased fruit/vegetable consumption were the preferred lifestyle modifications and did not differ by race. Race and exercise were associated; a majority of whites were engaged in exercise whereas this was not so for African Americans.

Conclusions: Although exercise as a preferred lifestyle modification habit does not differ by race, implementation of such a behavior does. This may be related to differing income levels. When counseling patients, physicians must be prepared to ask what may hinder the adoption of such behavior and be prepared to offer possible solutions to overcoming such factors. (J Am Board Fam Med 2008;21: 358-360.)

Hypertension is a major contributor to morbidity and mortality in the United States, ${ }^{1}$ with a disease prevalence of $31.3 \% .^{2}$ African-Americans are disproportionately affected and suffer greater morbidity and mortality. ${ }^{3}$ Lifestyle modification (low-

This article was externally peer reviewed.

Submitted 25 July 2007; revised 14 September 2007; accepted 20 September 2007.

From the Ohio State University Department of Family Medicine (RW), Department of Medicine, Division of Cardiology (DF), the School of Medicine (DL, JM), and the College of Optometry (LTS, LAJ), Columbus.

Funding: Supported, in part, by the National Institutes of Health/National Eye Institute grant EY014792.

Conflict of interest: none declared.

Corresponding author: Randy Wexler, MD, MPH, FAAFP, Department of Family Medicine, The Ohio State University, B0902B Cramblett Hall, 456 West 10th Ave, Columbus, Ohio 43210 (E-mail: Randy.Wexler@osumc.edu). sodium diet, exercise, moderate alcohol consumption, the Dietary Approaches to Stop Hypertension plan, and weight loss) is recommended for all patients with hypertension. ${ }^{1}$ Many patients fail to adopt recommended lifestyle modifications. Although the complex interaction of various factors contributes to this problem, socioeconomic status (SES) probably plays a significant role.

\section{Methods}

We conducted an anonymous voluntary survey of patients with hypertension who received their health care at 2 offices within the Ohio State University Primary Care Practice-Based Research Network. We approached all patients who had a diagnosis of hypertension, based on a presenting complaint during any routine office visit or as doc- 
umented in their respective chart, from November 2005 through March 2006. Our rate of participation was $80 \%$.

The survey consisted of questions used to determine basic demographics and stage of change for diet and exercise in hypertensive patients. The stage-of-change question format followed the wording used and validated by Prochaska and DiClemente $^{4}$ :

Have you changed your diet (reduced sodium, decreased alcohol, lowered fat) or exercise habits to help lower your blood pressure?

Responses were provided by choosing 1 of 5 options: $5=$ Yes, I have been for more than 6 months; $4=$ Yes, I have been for less than 6 months; $3=$ No, but I intend to in the next 30 days; $2=$ No, but $I$ intend to in the next 6 months; $1=\mathrm{No}$, and I do NOT intend to in the next 6 months. Patients were then asked which lifestyle choice they preferred: exercise, weight loss, reduced salt, increased fruits and vegetables, or moderation of alcohol.

\section{Results}

Two hundred eighty-five patients participated in the survey. We received 244 complete responses. Mean age was 54 years; $57 \%$ were women. Eighteen percent had a history of heart disease, $46 \%$ were married, $51 \%$ were white, and $43 \%$ were African-American. For both groups, 30\% were high school graduates. Among African-Americans, $11 \%$ were college graduates; among whites, $12 \%$ were college graduates. Thirty-five percent of African-Americans earned less than $\$ 25,000$ per year although this was true for only $23 \%$ of whites.

A test of the hypothesis that responses were equally distributed across the 5 stages of change was rejected, with $P \leq .0001$. For diet and, to a lesser extent, exercise, choice is concentrated in the more positive action (options 4 and 5). $\chi^{2}$ tests found a statistically significant relationship between exercise and race $(P=.01)$ (Tables 1 and 2). A majority of Caucasians were likely to be engaged in exercise, whereas this was not so for AfricanAmericans. A statistically significant finding $(P=$ .002 ) was that the odds for choosing option 3 ("No, but I intend to exercise in the next 30 days") over option 5 ("Yes, I have been for more than 6 months") were approximately 3 times higher for African-American patients than for white patients.

There were statistically significant differences in the popularity of the action items listed. Exercise
Table 1. Diet and Exercise Status as a Function of the Stages of Change Model

\begin{tabular}{cc}
\hline Responses* $^{*}$ & Percent \\
\hline Diet $(\mathrm{n}=244)$ & 14 \\
1 & 8 \\
2 & 12 \\
3 & 27 \\
4 & 39 \\
5 & \\
Exercise $(\mathrm{n}=244)$ & 10 \\
1 & 10 \\
2 & 25 \\
3 & 25 \\
4 & 30 \\
5 & \\
\hline
\end{tabular}

*Responses to the survey question "Have you changed your diet (reduced sodium, decreased alcohol, lowered fat) or exercise habits to help lower your blood pressure?" were provided as a choice among 1 of 5 options:

$5=$ Yes, I have been for more than 6 months;

$4=$ Yes, I have been for less than 6 months;

$3=$ No, but I intend to in the next 30 days;

$2=$ No, but I intend to in the next 6 months; or

$1=$ No, and I do not intend to in the next 6 months.

(95\% CI, 0.85-0.94) and increased fruit/vegetable consumption (95\% CI, 0.86-0.95) were preferred over a reduction in salt, weight loss, and moderation of alcohol consumption. There were no statistically significant differences in the relative popularity of the action items based on race.

\section{Discussion}

The morbidity and mortality of coronary artery disease has been found to be associated with lower SES. ${ }^{5}$ Improved control of hypertension has a positive impact on coronary artery disease. ${ }^{5,6}$ Exercise is an important lifestyle modification recommended for all patients diagnosed with hypertension. ${ }^{1}$ In our study, African-American patients with hypertension were much more likely to be thinking about exercising as opposed to actively exercising when compared with white patients $(36 \%$ vs $17 \%$, respectively). Previous studies have suggested barriers to exercise and other desired lifestyle behaviors for patients of lower SES include higher neighborhood crime rates, ${ }^{6}$ lower social support, ${ }^{6}$ and poor baseline health in general. ${ }^{6}$

The educational level did not differ between groups. African-Americans were just as likely as white patients to have graduated from high school (30\% for 
Table 2. Diet and Exercise Status, by Race, as a Function of the Stages of Change Model

\begin{tabular}{|c|c|c|c|c|c|c|}
\hline & \multicolumn{5}{|c|}{ Response (\%)* } & \multirow[b]{2}{*}{$P$} \\
\hline & 1 & 2 & 3 & 4 & 5 & \\
\hline $\operatorname{Diet}(\mathrm{n}=228)$ & & & & & & .29 \\
\hline White & 16 & 9 & 11 & 24 & 41 & \\
\hline African-American & 9 & 7 & 15 & 30 & 39 & \\
\hline Exercise $(\mathrm{n}=228)$ & & & & & & .01 \\
\hline White & 13 & 9 & 17 & 26 & 35 & \\
\hline African-American & 7 & 10 & 36 & 25 & 23 & \\
\hline
\end{tabular}

*Responses to the survey question "Have you changed your diet (reduced sodium, decreased alcohol, lowered fat) or exercise habits to help lower your blood pressure?" were provided as a choice among 1 of 5 options:

$5=$ Yes, I have been for more than 6 months;

$4=$ Yes, I have been for less than 6 months;

$3=$ No, but I intend to in the next 30 days;

$2=\mathrm{No}$, but I intend to in the next 6 months; or

$1=$ No, and I do not intend to in the next 6 months.

both groups) or college (11\% for African Americans and $12 \%$ for whites). There was, however, a large discrepancy in income level. African-Americans were more likely to earn less than $\$ 25,000$ per year than whites (35\% vs $23 \%$, respectively) and were less likely to earn more than $\$ 75,000$ compared with whites (11\% vs $19 \%$, respectively). Though the discrepancy between education and income is provocative, our study was not designed to evaluate this. It does, however, suggest avenues in need of further study. Our findings suggest that lower income is positively associated with thinking about exercising rather than engaging in exercise among African-Americans with hypertension.

\section{References}

1. Chobanian A, Bakris G, Black H, et al. Seventh Report of The Joint National Committee on Prevention, Detection, Evaluation, and Management of High Blood Pressure (JNC-7). Hypertension 2003;42:1206-52.
2. Fields L, Burt V, Cutler J, Hughes J, Rocella E, Sorlie P. The burden of adult hypertension in the United States 1999-2000: a rising tide. Hypertension 2004;44:1-7.

3. American Heart Association. Heart disease and stroke statistics 2006 update. Dallas (TX): American Heart Association; 2006.

4. Prochaska J, DiClemente C. Stage and processes of self-change in smoking: towards an integrative model of change. J Consult Clin Psychol 1983;51: $390-5$.

5. Lynch JW, Kaplan GA, Cohen RD, Tuomilehto, Salonen JT. Do cardiovascular risk factors explain the relationship between socioeconomic status, risk of all-cause mortality, cardiovascular mortality, and acute myocardial infarction? Am J Epidemiol 1996; 144:934-42.

6. Brown A, Ang A, Pebley AR. The relationship between neighborhood characteristics of self-related health for adults with chronic conditions. Am J Pub Health 2007:97:926-32. Epub 2007 Mar 29. 